\title{
Relationship of Socio-Economic Status (SES) with Depression of Senior Citizens Living in Himachal Pradesh and Uttar Pradesh State of India
}

\author{
Dr. Ashwani Kumar* \\ Department of Physical Education, NNPG, College, Nawabganj Gonda (U.P)-INDIA
}

*Corresponding Author: Dr. Ashwani Kumar, Department of Physical Education, NNPG, College, Nawabgani Gonda (U.P)-INDIA

\begin{abstract}
The main objective of the study was to investigate the relationship of Socio-economic Status (SES) with Depression of Senior Citizens Living in Himachal Pradesh and Uttar Pradesh State of India. 2000 sample were selected on the bases of simple random method viz: 1000 of each State. 500 male and 500 female gender wise categories were selected of each state. The study was conducted by using the Standardized Questionnaire for measuring the Depression level of Senior Citizens of both states i.e.: Zung Self-Rating Depression Scale (SDS). The data collected was statistically analyzed by using Percentage and Chi Square was specially used to find out the significance difference in between Socio-economic Status (SES) \& Depression Level of Senior Citizens. On the basis of statistical analysis it can be briefly concluded that senior citizens of Himachal Pradesh and Uttar Pradesh state differed significantly in respect to their Socio-economic Status with Depression Level.
\end{abstract}

Keywords: Socio-Economic Status, Depression, Senior Citizens, Himachal \& Uttar Pradesh State

\section{INTRODUCTION}

Senior Citizen is a common euphemism for an elderly person in both UK and US, and it implies or means that the person is retired. This in turn usually implies or in fact means that the person is over the retirement age, which varies according to country.

Synonyms include pensioner in UK and retiree and senior in US. Some dictionaries describe widespread usage of "senior citizen" for people over the age of 65. "Senior citizen" is replacing the term old-age pensioner traditionally used in UK. When defined in an official context, senior citizen is often used for legal or policy-related reasons in determining who is eligible for certain benefits available to the age group. The term was apparently coined in 1938 during a political campaign. It has come into widespread use in recent decades in legislation, commerce, and common speech. Especially in less formal contexts, it is often abbreviated as "senior(s)", which is also used as an adjective.

In commerce, some businesses offer customers of a certain age a "senior discount". The age at which these discounts are available vary between 55,60 or 65 , and other criteria may also apply. Leone et al (2012): Non-communicable diseases account for more than 50\% of deaths in adults aged 15-59 years in most low income countries. Depression and diabetes carry an enormous public health burden, making the identification of risk factors for these disorders an important strategy. While socioeconomic inequalities in chronic diseases and their risk factors have been studied extensively in highincome countries, very few studies have investigated social inequalities in chronic disease risk factors in low or middle-income countries. Documenting chronic disease risk factors is important for understanding disease burdens in poorer countries and for targeting specific populations for the most effective interventions. The aim of this review is to systematically map the evidence for the association of socio-economic status with diabetes and depression co morbidity in low and middle income countries. The objective is to identify whether there is any evidence on the direction of the relationship: do co-morbidities have an impact on socio-economic status or vice versa and whether the prevalence of diabetes combined with depression is associated with socio-economic status factors within the general population. To date no other study has reviewed the evidence for the extent and nature of this relationship. By systematically mapping the evidence in the broader sense we can 
identify the policy and interventions implications of existing research, highlight the gaps in knowledge and suggest future research. Only 14 studies were found to analyze the associations between depression and diabetes co morbidity and socio-economic status. Studies show some evidence that the occurrence of depression among people with diabetes is associated with lower socioeconomic status. The small evidence base that considers diabetes and depression in low and middle income countries is out of step with the scale of the burden of disease.

Depression (major depressive disorder) is a common and serious medical illness that negatively affects how you feel, the way you think and how you act. Fortunately, it is also treatable. Depression causes feelings of sadness and/or a loss of interest in activities once enjoyed. It can lead to a variety of emotional and physical problems and can decrease a person's ability to function at work and at home.

\section{OBJECTIVE OF THE STUDY}

The main objective of the study was to investigate the relationship of Socio-economic Status (SES) with Depression of Senior Citizens Living in Himachal Pradesh and Uttar Pradesh State of India.

\subsection{Hypothesis of the Study}

It was hypothesized that there will be significant difference in between Socio-economic Status (SES) \& Depression of Senior Citizens living in Himachal Pradesh and Uttar Pradesh State of India.

\section{DESIGN OF THE STUDY}

2000 sample were selected on the bases of simple random method viz: 1000 of each State. 500 male and 500 female gender wise categories were selected of each state. The study was conducted by using the Standardized Questionnaire for measuring the Depression level of Senior Citizens of both states i.e.: Zung Self-Rating Depression Scale (SDS).

\subsection{Procedure of Data Collection}

The data was collected by administering the above mentioned tool on the Senior Citizens of Himachal Pradesh and Uttar Pradesh State.

The Researcher personally visited the villages and towns of the districts of Himachal Pradesh and Uttar Pradesh which were included in the sample. Apart from this, researcher also visited and arranged meetings at various old age homes which were located in the said districts. The researcher also took the help of various NGOs working for the welfare of Senior Citizen in the said districts for data collection.

\subsection{Statistical Analysis and Interpretations of the Data}

Table1. Showing the Relationship of Socio-economic Status (SES) with Depression of Senior Citizens living in Himachal Pradesh and Uttar Pradesh State of India

\begin{tabular}{|c|c|c|c|c|c|c|c|c|c|c|}
\hline \multirow{2}{*}{$\begin{array}{c}\text { Depression } \\
\text { Category }\end{array}$} & \multicolumn{10}{|c|}{ UES Category } \\
\cline { 2 - 11 } & \multicolumn{2}{|c|}{ Upper } & \multicolumn{2}{c|}{ Middle } & Lower Middle & Upper Lower & \multicolumn{2}{c|}{ Lower } \\
\cline { 2 - 11 } & H.P. & U.P. & H.P. & U.P. & H.P. & U.P. & H.P. & U.P. & H.P. & U.P. \\
\hline High & 8 & 19 & 16 & 56 & 49 & 54 & 33 & 39 & 27 & 17 \\
& $(16.33)$ & $(23.75)$ & $(15.69)$ & $(28.72)$ & $(12.47)$ & $(14.21)$ & $(12.99)$ & $(17.33)$ & $(13.37)$ & $(14.17)$ \\
\hline Average & 23 & 49 & 55 & 110 & 225 & 233 & 119 & 127 & 103 & 83 \\
& $(46.94)$ & $(61.25)$ & $(53.92)$ & $(56.41)$ & $(57.25)$ & $(61.32)$ & $(46.85)$ & $(56.45)$ & $(50.99)$ & $(69.16)$ \\
\hline Normal & 18 & 12 & 31 & 29 & 119 & 93 & 102 & 59 & 72 & 20 \\
& $(36.73)$ & $(15)$ & $(30.39)$ & $(14.87)$ & $(30.28)$ & $(24.47)$ & $(40.16)$ & $(26.22)$ & $(35.64)$ & $(16.67)$ \\
\hline Total (N) & 49 & 80 & 102 & 195 & 393 & 380 & 254 & 225 & 202 & 120 \\
\hline$\left(\chi^{2}\right)$ & \multicolumn{7}{|c|}{8.087} & \multicolumn{7}{|c|}{12.751} & \multicolumn{7}{|c|}{3.353} & \multicolumn{2}{c|}{10.527} & \multicolumn{2}{c|}{13.829} \\
\hline
\end{tabular}

Figure in parenthesis indicates the percentage df. $=2$, tab. $=5.991$ at 0.05 level of significance

The above table no-I shows that senior citizens of both states having different socio economic background in majority showed moderate depression level.

The upper lower class (40.16\%), upper class $(36.73 \%)$ and lower class $(35.64 \%)$ senior citizens of Himachal Pradesh reported normal depression level than middle (30.39\%) and lower middle (30.28\%) respectively. 
In Uttar Pradesh the highest percentage of senior citizens having normal depression were found in upper lower $(26.22 \%)$ and lower middle $(24.47 \%)$ class, while the percentage of normal depression is noted averagely around $15 \%$ in other classes.

The percentage of highly depressive senior citizens $(28.72 \%)$ is found more in middle class followed by upper class $(23.75 \%)$ of Uttar Pradesh, while in Himachal.

The percentages of highly depressive individual is ranging from 12.99 to $13.37 \%$ in lower middle, upper lower and lower classes except upper class. The maximum figure of highly depressive person in Himachal is found $16.33 \%$ in upper class and $15.69 \%$ in middle class.

The calculated chi square of lower middle class 3.353 is found less than the tabulated value at 0.05 level of significance, which concludes that senior citizen of upper class of both states do not differ significantly in respect to depression.

Table also concludes that senior citizens of upper class, middle, upper lower and lower class of Uttar Pradesh and Himachal Pradesh differed significantly in respect to depression, as the calculated square $8.087,12.75,10.257$ and 13.289 respectively is found significant at 0.05 level of significance.

Depression is a dangerous state of mind which can affects the mental and physical behavior of an individual for one day, one week, and one month or may be continued for one year and more. The depression level is closely associated with up and down movements of the life. Some morning news on stock exchange may increase your depression level or some time raise in bank interest on saving can bring the depression normal. Similarly, hike in diesel \& petrol prices may caused a person depressed in Uttar Pradesh because the agriculture of Uttar Pradesh is depends totally up on the tube bell irrigation and machines, while in Himachal agriculture is non-machine and depends totally up on monsoon. So, the depression may also be varied in individual to individual or group to group, community to community, state to state and country to country. The same is depicted with the help of graph in Fig-I.

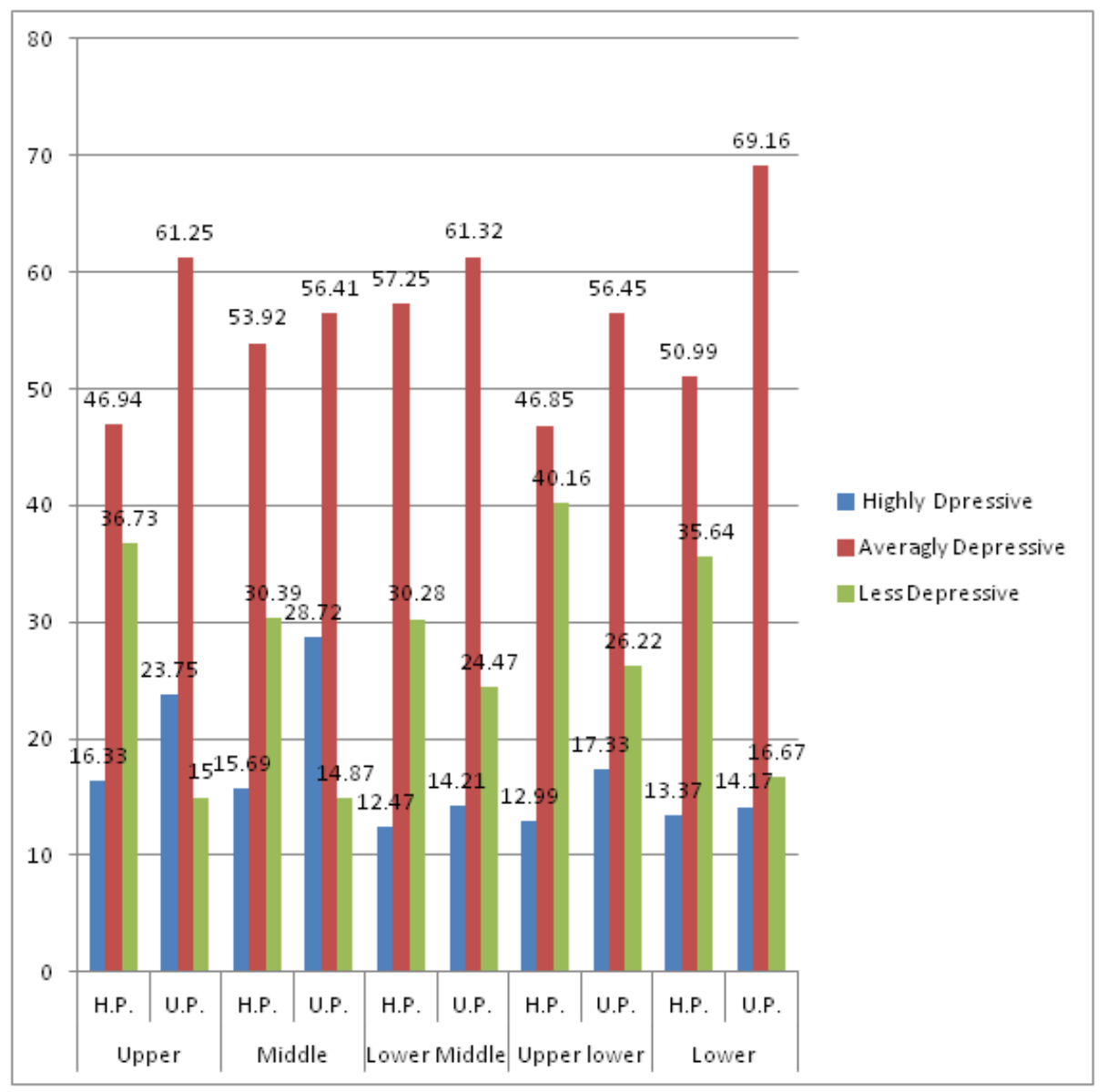

Figure1. Showing the percentage of Depression Level of Senior Citizens having different Socioeconomic Strata of Himachal Pradesh and Uttar Pradesh State of India 


\section{FINDINGS OF THE STUDY}

The followings were the main findings of the study:-

- The upper lower class (40.16\%), upper class (36.73\%) and lower class (35.64\%) senior citizens of Himachal Pradesh reported normal depression level than middle $(30.39 \%)$ and lower middle $(30.28 \%)$ respectively.

- The percentage of highly depressive senior citizens $(28.72 \%)$ is found more in middle class of Uttar Pradesh followed by upper class $(23.75 \%)$, while in Himachal the percentages of highly depressive individual is ranging from 12.99 to $13.37 \%$ in lower middle, upper lower and lower classes except upper class.

- The senior citizen of upper class of both states does not differ significantly in respect to depression, as chi square of lower middle class 3.353 is found insignificant.

- The senior citizens of upper class, middle, upper lower and lower class of Uttar Pradesh and Himachal Pradesh differed significantly in respect to depression, as the calculated square 8.087, $12.75,10.257$ and 13.289 respectively is found significant at 0.05 level of significance.

\section{REFERENCES}

[1] Buchberger B, Huppertz H, Krabbe L, Lux B, Mattivi JT, Siafarikas A (2016). "Symptoms of depression and anxiety in youth with type 1 diabetes: (Systematic Review). doi:10.1016/j.psyneuen.2016.04.019. PMID 27179232.

[2] Davey CG, Yücel M, Allen NB (2008). "The emergence of depression in adolescence: development of the prefrontal cortex and the representation of reward". Neuroscience and Biobehavioral Reviews. 32 (1): 1-19.

[3] Davison, Gerald C. (2008). Abnormal Psychology. Toronto: Veronica Visentin. ISBN 978-0-470-84072-6.

[4] American Psychiatric Psychiatric Publishing. ISBN 978-0-89042-555-8.

[5] Leone et al: "Diabetes and Depression Co -morbidity and Socio-Economic Status in Low and Middle Income Countries (LMICs): a Mapping of the Evidence" Houghton St, London, Nov-2012.

[6] Zingone F, Swift GL, Card TR, Sanders DS, Ludvigsson JF, Bai JC (Apr 2015). "Psychological morbidity of celiac disease: A review of the literature". United European Gastroenterol J (Review). 3 (2).

[7] https://www.psychiatry.org/patients-families/depression/what-is-depression

Citation: Dr. Ashwani Kumar. "Relationship of Socio-Economic Status (SES) with Depression of Senior Citizens Living in Himachal Pradesh and Uttar Pradesh State of India" International Journal of Sports and Physical Education (IJSPE), vol 5, no.1, 2019, pp. 26-29. doi: http://dx.doi.org/ 10.20431/24546380.0501005 .

Copyright: (C) 2019 Authors. This is an open-access article distributed under the terms of the Creative Commons Attribution License, which permits unrestricted use, distribution, and reproduction in any medium, provided the original author and source are credited. 